\title{
Osteoporosis and osteopenia in the distal forearm predict all-cause mortality independent of grip strength: 22 year follow-up in the population-based Tromsø Study
}

\section{Word count Mini-abstract: 49}

Low bone mineral density (BMD) gives an increased risk of fractures, which can lead to premature death. Can BMD of the wrist predict mortality? BMD consistent with osteopenia and osteoporosis gave a significantly increased risk of death for both men and women in a general population in Troms $\varnothing$, Norway.

\section{Word count abstract: 249}

\section{Purpose}

To investigate if bone mineral density (BMD) levels of the distal forearm, consistent with osteopenia and osteoporosis, can predict mortality and if grip strength is an effect modifier.

\section{Methods}

The study population constituted 6565 participants aged 50-79 years at baseline in the Troms $\emptyset$ study wave 4 conducted in 1994-5. Forearm BMD measured by SXA was categorized as "normal”, "osteopenia” or “osteoporosis” following WHO’s definition. Cox regression with all-cause mortality as the outcome over 22 years of follow-up was performed for men and women separately, adjusting for health-related factors, as well as BMD by grip strength interaction. A secondary analysis with 15 years follow-up also adjusted for hip fractures and osteoporotic fractures.

\section{Results}

During follow-up, 3176 of participants died (47\%). Those categorized as osteoporotic had higher mortality hazard ratio (HR) compared to those with normal BMD; Men HR=1.37 (95\% confidence interval (CI) 1.19, 1.58) and women $\mathrm{HR}=1.32(1.14,1.53)$, adjusted for age, body mass index, physical activity, smoking habits, education, health status, chronic diseases and grip strength. Corresponding HRs for osteopenia were; Men $\mathrm{HR}=1.13(1.00,1.27)$ and women $\mathrm{HR}=1.17(1.01,1.35)$. Further adjustments for fractures did only marginally attenuate the results, and HRs were still significant. There was no grip strength by BMD interaction.

\section{Conclusion}

Men and women with low distal forearm BMD-values, consistent with osteoporosis or osteopenia, had an increased mortality compared to normal BMD participants. High grip strength did not modify this association, and the association remained after adjustment for a range of health-related factors. 
Keywords:

Osteoporosis, osteopenia, bone mineral density, mortality, grip strength, hip fracture

Word count article: 3579

\section{Introduction}

Osteoporosis constitutes an important public health concern with its high incidence in Western populations, and progressive prevalence in Asia [1, 2]. Osteoporosis is known to vary by gender and age [3]. It is often defined as a disease of women because the prevalence and fracture rates are much higher among females, but once an osteoporotic hip fracture has occurred, excess mortality has been found to be higher in men [3, 4]. The incidence of osteoporosis is increasing with age, occurring mainly above the age of 50 years [5].

Osteopenia is the precursor of osteoporosis. The World Health Organization (WHO) Study Group on

Osteoporosis has defined osteopenia and osteoporosis as bone mineral density (BMD) of more than 1 and 2.5 standard deviations (SDs), respectively, below the mean BMD of the young, white, female adult reference population [6]. Based on data from the United States, it has been estimated that 30 percent or more of all postmenopausal, white women have osteoporosis [7]. The lifetime risk of any fracture of the hip, spine, proximal- or distal forearm, all considered typical osteoporotic fractures, was estimated to be 46 percent in women and 22 percent in men from age 50 years onward in a Swedish population [8]. As life expectancy increases, the population burden of osteoporosis and related fragility fractures will increase [1,9].

51 A systematic review and meta-analysis from 2013 [10] found an inverse relationship between BMD and allcause mortality. The same result was found for women with type 2 diabetes [11]. An important pathway linking low BMD to mortality is via fractures, and hip fractures in particular. Furthermore, the association between BMD and mortality could be confounded by physical fitness, physical activity, body mass, smoking habits, level of education [4, 12-15] and by comorbidity such as stroke, angina, myocardial infarction, diabetes and asthma [16-18]. 
Grip strength measurements have been recommended in order to identify old people with sarcopenia [19] (low muscle mass and low muscle function). Low grip strength has also been found to predict disability, impaired quality of life, falls and mortality [20-22], while high grip strength may indicate resilience to aging [23].

Osteoporotic fractures of the proximal femur are particularly associated with excess mortality and studies have consistently found that this association increases with age [4, 24]. For distal forearm fractures however, excess mortality is found to be lower or non-significant [24], but a prior wrist fracture can increase the risk of any osteoporotic fracture later in life $[25,26]$. Recent studies have found that osteoporosis is more easily detected in the peripheral regions (wrist) than in the central regions (spine and hip) [27] and wrist BMD has better accuracy than lumbar BMD in diagnosing osteoporosis in postmenopausal women [28]. Measuring BMD in the distal forearm might reveal a BMD deficiency at an earlier stage and give better prerequisites for treatment and fracture prevention.

The main aim of this paper was to assess the predictive value of established definitions for osteopenia and osteoporosis in evaluating risk of mortality. Identifying individuals at high risk is crucial in order to provide interventions on amendable risk factors for osteopenia or osteoporosis. There have been previous studies on how mortality is affected by different treatments of osteoporosis, fracture types [4, 24, 29] and BMD values in various populations $[10,11,30]$. However, the association between osteoporosis and osteopenia of the distal forearm and mortality, and the possible mediating effect of grip strength has to the very best of our knowledge not been examined in a population-based study before. Thus an additional aim of this paper was to investigate if a strong grip modified the potential association between low BMD and mortality and whether the association was confounded by BMI, smoking, physical activity level, self-reported health status, level of education or chronic diseases such as angina, stroke, myocardial infarction, diabetes and asthma. We hypothesized that those with distal forearm BMD categorized as osteoporotic or osteopenic had a higher mortality risk compared to those with normal BMD-values, but that this increased risk could be partly counteracted by a high grip strength.

\section{Method}

\section{Study population}

5 The Troms $\varnothing$ Study was initiated in 1974 and is a longitudinal, population based, multi-purpose study focusing on 6 lifestyle-related diseases [31]. There have been seven study waves, and our study population is comprised of 
participants from the fourth wave, conducted in 1994-95. This wave included a bone densitometry measurement as a part of additional testing that was offered to all participants aged 55-74 years, all women aged 50-55 years and a random selection of 10-15 percent of participants aged 24-55 years and 74-85 years. In the current analyses, only participants aged 50-79 years were included. The attendance rate was 76 percent among men and 79 percent among women in this age group. Our study population consisted of 6565 participants, 3818 women with a mean age of 60.7 years $(\mathrm{SD}=7.4)$ and 2747 men with a mean age of 62.6 years $(\mathrm{SD}=6.4)$.

\section{Assessment of bone mineral density (BMD)}

Bone densitometry using SXA was performed on the non-dominant forearm at distal and ultra-distal sites with two single X-ray absorptiometry devices (DTX-100; Osteometer MediTech, Inc., Hawthorne, California). Further specification of the testing procedure can be found elsewhere [32]. No significant difference has been detected regarding precision of the distal and ultra-distal measurement [33]. The distal measurement was chosen for our analyses, including both radius and ulna. Osteopenia and osteoporosis were defined respectively as 1 and 2.5 SDs below the mean of young, healthy men and women (see below).

\section{Reference values}

Gender specific internal BMD reference values were created for osteopenia and osteoporosis, based on BMD values corresponding to 1 and 2.5 standard deviations below the mean BMD of healthy men and women aged 24-39 years in the Troms $\varnothing 4$ densitometry data. Besides gender and age range, the reference populations were defined by a dichotomous variable, "healthy" (Yes/no), which was based on the following disease-related questions: Do you have, or have you had a myocardial infarction? (Yes/no); Do you have, or have you had angina pectoris? (Yes/no); Do you have, or have you had a cerebral stroke/brain hemorrhage? (Yes/no); Do you have, or have you had asthma? (Yes/no); Do you have, or have you had diabetes? (Yes/no); What is your current state of health? (Poor/not so good/good/very good). Those who reported "good" or "very good" self-rated health combined with "no" on all the disease related questions were defined as "healthy", and this group was used when calculating reference values for categorization into "normal BMD”, "osteopenia" and "osteoporosis". Only including the "healthy" participants resulted in 252 women with a mean BMD-value of $0.471 \mathrm{~g} / \mathrm{cm}^{2}(\mathrm{SD}=0.043)$ and 147 men with a mean BMD-value of $0.575 \mathrm{~g} / \mathrm{cm}^{2}$ (SD=0.045). Thus, 2.5 SD below mean BMD (osteoporosis) corresponded to $0.364 \mathrm{~g} / \mathrm{cm}^{2}$ in women and $0.464 \mathrm{~g} / \mathrm{cm}^{2}$ in men, and $1.0 \mathrm{SD}$ below mean (osteopenia) corresponded to $0.428 \mathrm{~g} / \mathrm{cm}^{2}$ in women and $0.531 \mathrm{~g} / \mathrm{cm}^{2}$ in men. 


\section{Ascertainment of deaths}

119 The outcome in this study was all-cause mortality. Data on each participant was linked, by the means of the

120 unique personal identification number, to the Norwegian Cause of Death Registry for assessment of death, and to 121 the National Registry for assessment of emigration. Participants were followed from baseline survey in 1994-95

122 until emigration, death or November $5^{\text {th }}, 2016$, whichever occurred first.

123

\section{Covariates}

125 Covariates known to be associated with lower BMD and mortality were selected a priori for inclusion as possible 126 confounders in addition to age and gender. Height and weight was measured by trained personnel in The Tromsø 127 Study and body mass index (BMI) was calculated as weight in kilograms divided by height in meters squared $128\left(\mathrm{~kg} / \mathrm{m}^{2}\right)$ and grouped as: low $=$ BMI $\leq 20.00 \mathrm{~kg} / \mathrm{m}^{2}$, normal $=20.01 \mathrm{~kg} / \mathrm{m}^{2}$ to 25.00 , overweight $=25.01$ to 30.00

$129 \mathrm{~kg} / \mathrm{m}^{2}$ and obese $>30.00 \mathrm{~kg} / \mathrm{m}^{2}$. Smoking was self-reported, and categorized in three groups as current, previous, 130 or never-smoker. Education level was based on years of completed education grouped into five levels ranging 131 from "7-10 years primary/secondary school” to "college/university 4 or more years". Level of physical activity 132 was self-reported by counting hours of light physical activity (not sweating or out of breath) and hard physical 133 activity (sweating and/or out of breath) during a typical week in the previous year. The number of hours per 134 week for each variable was categorized in four groups: none, less than one, one to two, three or more. Chronic 135 diseases were self-reported in Tromsø 4 with alternatives "yes" or "no" following questions about stroke, 136 myocardial infarction, angina, diabetes or asthma in their medical history along with questions regarding self137 perceived health categorized as: very good, good, not so good, and poor. Grip strength of the non-dominant hand 138 was measured in bar using a Martin vigorimeter. Each participant was allowed two attempts, and the highest 139 score was recorded and used in analyses. Grip strength was grouped into gender specific quartiles. Records for 140 fractures were available for all participants until February 22th 2010. Fractures of the femur neck and 141 trochanter were defined as "hip fractures". These in addition to distal fractures of ulna and radius were defined as 142 "osteoporotic fractures". Vertebral fractures were not reported in the material.

\section{Statistics}

145 Separate analyses were conducted for men and women. A Cox proportional hazards survival model was used to 146 assess the associations between T-score groups based on distal forearm BMD and mortality. We successively 
147 adjusted for health- and lifestyle-related variables in three models; model 1: (attained) age, model 2: model 1+

148 BMI, level of physical activity, smoking habits and category of completed education, model 3: model $2+$ self-

149 reported health status and self-reports of chronic diseases including asthma, diabetes, angina pectoris, stroke and

150 myocardial infarction. In addition, grip strength by BMD interaction was tested in a fourth model. Fractures were

151 included in a secondary analysis since fracture data was only available until February 22th 2010, giving a shorter

152 follow-up period. Model 1 is minimally adjusted for age (attained), without fracture variables. Model 2 and 4

153 minimally adjusted for age (attained) and hip fractures or osteoporotic fractures. Model 3 and 5 fully adjusted in

154 addition to hip fractures or osteoporotic fractures. The fracture variables were modelled as time-dependent

155 covariates in order to avoid immortal time-bias. The proportional hazard (PH) assumption was inspected visually

156 and by formal tests based on scaled Schoenfeld residuals. Statistical significance was determined by an alpha

157 level of 0.05. The statistical analysis was carried out with Stata/SE 15.

158

\section{Results}

160 During follow up in the main analysis, $3176(46.8 \%)$ of the 6790 participants died, 1538 women and 1638

161 men. Fifty-four participants were censored due to emigration. The mean BMD-value of the total study

162 population 50 to 79 years was $0.458 \mathrm{~g} / \mathrm{cm}^{2}(\mathrm{SD}=0.094), 0.403 \mathrm{~g} / \mathrm{cm}^{2}(\mathrm{SD} 0.069)$ in women and $0.533 \mathrm{~g} / \mathrm{cm}^{2}(\mathrm{SD}$

163 0.067) in men (Table 1). According to the definition, $1512(38 \%)$ female participants had normal BMD, 1329

$164(34 \%)$ had osteopenia and 1104 (28\%) had osteoporosis. Corresponding numbers in men were $1575(55 \%), 870$

$165(31 \%)$ and $400(14 \%)$ (Table 1 and 2).

166

167 In our secondary analysis including fracture data, 1242 women and 434 men experienced a fracture during 15

168 years follow-up from baseline to February 22th 2010. Among women, 265 experienced a hip fracture and 479

169 experienced a distal forearm fracture. Corresponding numbers among men were 132 and 194.

170

171 Participants categorized as having osteoporosis were significantly older, had a lower BMI, lower grip strength,

172 performed less hard physical activity, had inferior self-reported health and a higher percentage had experienced a

173 stroke compared to those with normal BMD-values (Table 2). Among women, the osteoporosis group also

174 performed less light physical activity, they were lower educated and had a higher lifetime prevalence of angina

175 pectoris or a myocardial infarction than participants with normal BMD. Significantly more men were smokers in

176 the osteoporosis group than in the normal BMD group. 
178 Cox regression revealed a significantly higher mortality in both women and men with osteoporosis and

179 osteopenia compared to the normal BMD groups (Table 3). In the fully adjusted model, including adjustments

180 for age, BMI, level of education, physical activity, smoking, self-reported health, chronic diseases and grip

181 strength, the hazard ratio (HR) was 1.32 (95\% confidence interval (CI) 1.14 to 1.53 ) for women and 1.37 (95\%

182 CI 1.19 to 1.58) for men with osteoporosis compared to those with normal BMD. Corresponding HRs for

183 mortality in participants with osteopenia were 1.17 (95\% CI 1.01 to 1.35 ) in women and 1.13 (95\% CI 1.00 to

184 1.27) in men. There was no grip strength by BMD interaction in women $(\mathrm{p}=0.84)$ or in men $(\mathrm{p}=0.55)$, see Figure

1851 and 2 illustrating the effect of "low" (lowest quartile) and "high" (three highest quartiles) grip strength on the

186 association between BMD as a continuous variable and HR for mortality. Tests of the proportional hazards

187 assumption using scaled Schoenfeld residuals indicated some violation of proportionality of hazard. For

188 osteoporosis the HRs were comparable in the three time periods 1994-2000, 2001-2006, 2007-2016 in both

189 genders. For osteopenia, however, the HRs were slightly lower in the first time periods in men, while in women

190 they were comparable. Despite this slight violation of PH, results are presented as an average for the whole

191 period.

192 In the secondary analysis, adjusting for hip fractures or osteoporotic fractures did not explain the increased

193 mortality among participants with osteoporosis. The association between osteopenia and mortality was still

194 significant in women after adjusting for fractures, but not in men (Table 4).

195

\section{Discussion}

197 To the best of our knowledge, this is the first population-based study to examine the association between

198 osteoporosis and osteopenia of the distal forearm and mortality, and the possible mediating effect of grip

199 strength. We found a statistically significant association between osteopenic and osteoporotic BMD-levels of the 200 distal forearm and increased mortality rate in both women and men.

202 The strengths of the present study include the population-based design, standardized objective measures of bone

203 mineral density and grip strength, a large sample size and a long follow-up of 22 years with updated time of

204 death from as recently as November 2016. The population consists of people living in both rural and urban areas

205 and the study had a high attendance rate (about 78\%). 
However, the study is not without limitations. Self-reported variables challenge the internal validity of any study

$208[34,35]$. State of health, presence of chronic diseases, level of physical activity, education and smoking habits

209 are self-reported variables and might be subject to over- or under-estimation due to recall bias [36] or socially

210 desirable responding (SDR) [37]. This can in turn lead to an under-estimation of the potential association

211 between variables. Though this could be the case with some of the variables mentioned above, the outcome in

212 the current analysis was the registry-based hard endpoint of deaths while our main exposure variables (BMD and

213 grip strength) were measured objectively.

215 We controlled for variables that were measured at baseline in 1994/5. During the follow-up of 22 years, it is

216 likely that some variables changed, especially the presence of chronic diseases since it is well known that

217 comorbidity increases in older age. The participants may also have experienced significant changes in BMD

218 during follow-up that could be associated with excess mortality. This could be subject for further research.

220 We created our own reference values in order to define osteopenia and osteoporosis for our population, but the

221 association between BMD as a continuous variable and mortality was also analyzed, allowing the reader to study

222 the whole spectrum of BMD independent of our categorization into osteoporosis, osteopenia and normal BMD.

223 Modern methods for BMD-testing has changed over the past 22 years and we were unsuccessful in retrieving

224 external reference-values for SXA of the distal forearm. There are both strengths and limitations in creating our

225 own reference values. We have no guarantee that our reference groups are similar to those used in other studies

226 and the variation within the reference group warrants the size of $1 \mathrm{SD}$ which in turn make out the cut-off values.

227 However, this resulted in 28 percent of the women being categorized as osteoporotic and this is comparable to

228 other findings in Caucasian women [7], considering that the oldest old were not included in this study. A

229 strength of creating a reference group from the same study is that they share the same geographical and cultural

230 affiliation, we know how the BMD has been measured and tests are performed by the same professionals,

231 following the same protocols as in the main analyses.

232 Dementia and other cognitive impairments increase the risk of mortality. $6.1 \%$ of all deaths in Norway in 2016

233 were registered with dementia as the underlying cause of death [38]. Cognitive assessments were not

234 incorporated in Troms $\varnothing 4$ so we could not control for cognitive impairments or dementia at baseline in our

235 analysis, however, later study waves including the same population revealed that a low proportion of the

236 participants had cognitive impairments, with 7.3\% scoring low on one or more of the cognitive tests in addition 
to self-report of memory problems. Out of these, only one participant had dementia. It is therefore unlikely that

238 dementia confounded the association we found between osteoporosis/osteopenia and mortality.

240 Our findings indicate that BMD measurements of the distal forearm has a predictive value in mortality risk

241 assessment and mortality can be predicted using the commonly accepted T-values of -1 and -2.5 for osteopenia

242 and osteoporosis, though only demonstrated on a group level. In evaluating an individual's mortality risk,

243 osteopenia and osteoporosis should be viewed as independent risk factors of death that will add to the total risk

244 along with other known risk factors.

246 The association between mortality and osteoporosis was slightly stronger in men while the association with

247 osteopenia was somewhat stronger in women, indicating that smaller deficiencies in BMD might be more serious

248 in women. However, the between-gender differences are not large enough to make such assumptions based on

249 this material. The association between osteoporosis and increased mortality was still significant in both men and

250 women after adjusting for fractures, indicating that there might be a more complex relationship between low

251 BMD and mortality risk than we are currently aware of. Several authors have found an inverse relationship

252 between BMD and risk of cardiovascular disease and -death $[39,40]$. Although we controlled for myocardial

253 infarction and angina, these variables were measured at baseline and more cases probably occurred during

254 follow-up, potentially more often among those with low BMD.

256 That our main analysis also show significantly higher mortality for osteopenic BMD-values suggests that it 257 might be valuable to initiate treatment measures already at this stage, though previous research debates the cost258 effectiveness of pharmacological treatment of osteopenia purely based on T-scores [41, 42]. Low BMD is mainly

259 seen as a risk factor of fractures, and it has been debated whether expensive medication is the right way to 260 prevent fractures as opposed to means of falls prevention [43]. However, one intervention does not exclude the 261 other, and falls prevention should be emphasized regardless of any medical prescriptions. In Norway, 262 osteoporosis appears to be both under-diagnosed and under-treated according to Devold et al. [44] who found 263 that one year after experiencing a hip fracture, only 14.6 percent of women and 4.2 percent of men used some 264 form of anti-osteoporotic medication. Grey et al. [29] found a significant reduction of mortality risk associated 265 with use of fracture-preventing medication in their meta-analysis and the effect was largest in older, frailer 
individuals. The decision to prescribe medication should in any case be based on a full assessment of the person's fracture risk and potential benefits of treatment.

268 In our study, a general population was screened for low BMD independent of prior indication of a BMDdeficiency. There are currently no routines for general screening of BMD in Norway, but our findings indicate that general BMD measurements can be of value in identifying individuals with higher risk of mortality.

271 Schousboe et al. [45] found that universal BMD-screening of the population combined with alendronate

272 therapy for those found to have osteoporosis is highly cost-effective for women aged 65 and older and may

273 be cost saving for ambulatory women aged 85 and older.

274 Based on our study, we cannot conclude whether treatment of low BMD will help decrease risk of 275 mortality or if the BMD deficiency is merely a marker for frailty. In practical terms, measured osteopenia 276 and osteoporosis in the distal forearm reveals individuals with increased risk of mortality, which warrants closer follow-up of these individuals by health care personnel.

278 In a previous analysis from the Troms $\emptyset 4$ study wave, high grip strength was associated with lower risk of mortality [20], yet grip strength did not attenuate or modify the higher mortality risk for participants with

280 osteoporosis or osteopenia in our analyses. Thus, these variables seem to be independently associated with 281 mortality.

In elderly people, most wrist fractures occur in individuals with low BMD who are relatively healthy and active 284 and have good neuromuscular function [46]. BMD is commonly measured after a low-energy trauma fracture.

285 Even though a wrist fracture in itself has not been found to increase the risk of mortality [24], our findings

286 indicate that an underlying BMD-deficiency in the forearm can have more serious implications, and measures should be taken accordingly with respect to current medical guidelines for prevention of fractures and treatment of osteoporosis.

\section{Conclusion}

292 Women and men with distal forearm BMD-values consistent with both osteoporosis and osteopenia had an increased all-cause mortality compared to people with normal BMD-values, independent of lifestyle- and health-

294 related variables. The association between BMD and all-cause mortality was not modified by hand grip strength. 


\section{References}

1. Cooper C, Cole Z, Holroyd C, Earl S, Harvey N, Dennison E, Melton L, Cummings S, Kanis J (2011) Secular trends in the incidence of hip and other osteoporotic fractures. Osteoporosis International 22:1277-1288

2. Cauley JA (2013) Public health impact of osteoporosis. Journals of Gerontology Series A: Biomedical Sciences and Medical Sciences 68:1243-1251

3. Pietschmann P, Rauner M, Sipos W, Kerschan-Schindl K (2009) Osteoporosis: an agerelated and gender-specific disease-a mini-review. Gerontology 55:3-12

4. Omsland TK, Emaus N, Tell GS, Magnus JH, Ahmed LA, Holvik K, Center J, Forsmo S, Gjesdal CG, Schei B (2014) Mortality following the first hip fracture in Norwegian women and men (1999-2008). A NOREPOS study. Bone 63:81-86

5. Bor A, Matuz M, Gyimesi N, Biczók Z, Soós G, Doró P (2015) Gender inequalities in the treatment of osteoporosis. Maturitas 80:162-169

6. Kanis JA (1994) Assessment of fracture risk and its application to screening for postmenopausal osteoporosis: synopsis of a WHO report. Osteoporosis international 4:368381

7. Kanis JA, Melton LJ, Christiansen C, Johnston CC, Khaltaev N (1994) The diagnosis of osteoporosis. Journal of bone and mineral research 9:1137-1141

8. Kanis J, Johnell O, Oden A, Sernbo I, Redlund-Johnell I, Dawson A, De Laet C, Jonsson B (2000) Long-term risk of osteoporotic fracture in Malmö. Osteoporosis international 11:669-674 9. Omsland T, Magnus J (2014) Forecasting the burden of future postmenopausal hip fractures. Osteoporosis International 25:2493-2496

10. Qu X, Huang X, Jin F, Wang H, Hao Y, Tang T, Dai K (2013) Bone mineral density and all-cause, cardiovascular and stroke mortality: a meta-analysis of prospective cohort studies. International journal of cardiology 166:385-393

11. Lenchik L, Register TC, Hsu F-C, Xu J, Smith SC, Carr JJ, Freedman BI, Bowden DW (2017) Bone Mineral Density of the Radius Predicts All-Cause Mortality in Patients With Type 2 Diabetes: Diabetes Heart Study. Journal of Clinical Densitometry

12. Fry PS, Debats DL (2006) Sources of life strengths as predictors of late-life mortality and survivorship. The International Journal of Aging and Human Development 62:303-334 13. Frith PA (2005) Impact of smoking, diabetes and hypertension on survival in the elderly: the Dubbo study. Medical Journal of Australia 182:495

14. Brown DC, Hayward MD, Montez JK, Hummer RA, Chiu C-T, Hidajat MM (2012) The significance of education for mortality compression in the United States. Demography 49:819-840

15. Wong PK, Christie JJ, Wark JD (2007) The effects of smoking on bone health. Clinical Science 113:233-241

16. Loprinzi PD, Addoh O (2017) Accelerometer-Determined Physical Activity and AllCause Mortality in a National Prospective Cohort Study of Adults Post-Acute Stroke. American Journal of Health Promotion 0890117117720061 17. Zahra A, Lee E-W, Sun L-y, Park J-H (2015) Cardiovascular disease and diabetes mortality, and their relation to socio-economical, environmental, and health behavioural factors in worldwide view. Public health 129:385-395

18. Ebmeier S, Thayabaran D, Braithwaite I, Bénamara C, Weatherall M, Beasley R (2017) Trends in international asthma mortality: analysis of data from the WHO Mortality Database from 46 countries (1993-2012). The Lancet 390:935-945 
19. Cruz-Jentoft AJ, Baeyens JP, Bauer JM, Boirie Y, Cederholm T, Landi F, Martin FC, Michel J-P, Rolland Y, Schneider SM (2010) Sarcopenia: European consensus on definition and diagnosisReport of the European Working Group on Sarcopenia in Older PeopleA. J. Cruz-Gentoft et al. Age and ageing 39:412-423

\section{Strand BH, Cooper R, Bergland A, Jørgensen L, Schirmer H, Skirbekk V, Emaus N} (2016) The association of grip strength from midlife onwards with all-cause and causespecific mortality over 17 years of follow-up in the Troms $\varnothing$ Study. J Epidemiol Community Health 70:1214-1221

21. Sayer AA, Syddall HE, Martin HJ, Dennison EM, Anderson FH, Cooper C (2006) Falls, sarcopenia, and growth in early life: findings from the Hertfordshire cohort study. American journal of epidemiology 164:665-671

22. Syddall HE, Martin HJ, Harwood RH, Cooper C, Sayer AA (2009) The SF-36: a simple, effective measure of mobility-disability for epidemiological studies. JNHA-The Journal of Nutrition, Health and Aging 13:57-62

23. Rantanen T, Masaki K, He Q, Ross GW, Willcox BJ, White L (2012) Midlife muscle strength and human longevity up to age 100 years: a 44-year prospective study among a decedent cohort. Age 34:563-570

24. Leboime A, Confavreux CB, Mehsen N, Paccou J, David C, Roux C (2010) Osteoporosis and mortality. Joint Bone Spine 77:S107-S112

25. Barrett-Connor E, Sajjan S, Siris E, Miller P, Chen Y-T, Markson L (2008) Wrist fracture as a predictor of future fractures in younger versus older postmenopausal women: results from the National Osteoporosis Risk Assessment (NORA). Osteoporosis International 19:607-613

26. Ahmed LA, Center JR, Bjørnerem Å, Bluic D, Joakimsen RM, Jørgensen L, Meyer HE, Nguyen ND, Nguyen TV, Omsland TK (2013) Progressively increasing fracture risk with advancing age after initial incident fragility fracture: the Troms $\emptyset$ study. Journal of Bone and Mineral Research 28:2214-2221

27. Abdelmohsen AM (2017) Comparison of Central and Peripheral Bone Mineral Density Measurements in Postmenopausal Women. Journal of chiropractic medicine 16:199203

28. Eftekhar-Sadat B, Ghavami M, Toopchizadeh V, Ghahvechi Akbari M (2016) Wrist bone mineral density utility in diagnosing hip osteoporosis in postmenopausal women. Therapeutic advances in endocrinology and metabolism 7:207-211 29. Grey A, Bolland M (2013) The effect of treatments for osteoporosis on mortality. Osteoporosis International 1-6

30. Miyake H, Kanazawa I, Sugimoto T (2018) Association of bone mineral density, bone turnover markers, and vertebral fractures with all-cause mortality in type 2 diabetes mellitus. Calcified tissue international 102:1-13

31. Jacobsen BK, Eggen AE, Mathiesen EB, Wilsgaard T, Njølstad I (2011) Cohort profile: the Troms $\varnothing$ study. International journal of epidemiology 41:961-967

32. Berntsen GKR, Fønnebø V, Tollan A, Søgaard AJ, Magnus JH (2001) Forearm Bone Mineral Density by Age in 7,620 Men and Women The Troms $\varnothing$ Study, a Population-based Study. American journal of epidemiology 153:

33. Berntsen GKR, Fønnebø V, Tollan A, Søgaard AJ, Joakimsen RM, Magnus JH (2000) The Troms $\varnothing$ Study:: Determinants of precision in bone densitometry. Journal of clinical epidemiology 53:1104-1112

34. Prince SA, Adamo KB, Hamel ME, Hardt J, Gorber SC, Tremblay M (2008) A comparison of direct versus self-report measures for assessing physical activity in adults: a systematic review. International Journal of Behavioral Nutrition and Physical Activity 5:56 
35. Gorber SC, Tremblay M, Moher D, Gorber B (2007) A comparison of direct vs. selfreport measures for assessing height, weight and body mass index: a systematic review.

397 Obesity reviews 8:307-326

398 36. Hassan E (2006) Recall bias can be a threat to retrospective and prospective research designs. The Internet Journal of Epidemiology 3:339-412 37. Van de Mortel TF (2008) Faking it: social desirability response bias in self-report research. Australian Journal of Advanced Nursing, The 25:40

38. Norwegian Cause of Death Registry (2017) Dødsårsakregisteret - Statistikkbank. Norwegian Institute of Public Health, http://statistikkbank.fhi.no/dar/. Accessed 28 June 2018 39. Marcovitz PA, Tran HH, Franklin BA, O’Neill WW, Yerkey M, Boura J, Kleerekoper M, Dickinson CZ (2005) Usefulness of bone mineral density to predict significant coronary artery disease. American Journal of Cardiology 96:1059-1063

40. von der Recke P, Hansen MA, Hassager C (1999) The association between low bone mass at the menopause and cardiovascular mortality. The American journal of medicine 106:273-278

41. McClung MR (2005) Osteopenia: to treat or not to treat? Annals of internal medicine 142:796-797

42. Seeman E (2004) Treatment Of Osteoporosis-Why, Whom, When And How To Treat. Indian Journal of Endocrinology and Metabolism 6:60

43. Järvinen TL, Sievänen H, Khan KM, Heinonen A, Kannus P (2008) Shifting the focus in fracture prevention from osteoporosis to falls. Bmj 336:124-126

44. Devold H, Søgaard A, Tverdal A, Falch J, Furu K, Meyer H (2013) Hip fracture and other predictors of anti-osteoporosis drug use in Norway. Osteoporosis International 24:12251233

45. Schousboe JT, Ensrud KE, Nyman JA, Melton LJ, Kane RL (2005) Universal Bone Densitometry Screening Combined with Alendronate Therapy for Those Diagnosed with Osteoporosis Is Highly Cost-Effective for Elderly Women. Journal of the American Geriatrics Society 53:1697-1704

46. Kelsey JL, Browner WS, Seeley DG, Nevitt MC, Cummings SR, Group SoOFR (1992) Risk factors for fractures of the distal forearm and proximal humerus. American Journal of Epidemiology 135:477-489 
Table 1. BMD-values of women and men aged 50-79 years in the Troms $\phi 4$ study, categorized as "normal", "osteopenia" and "osteoporosis" and number of deaths within age groups of 5 years.

\begin{tabular}{|c|c|c|c|c|c|c|}
\hline Age group & $\mathbf{N}$ & $\begin{array}{c}\text { Mean BMD } \\
\text { (SD) }\end{array}$ & $\begin{array}{c}\% \\
\text { Normal }\end{array}$ & $\begin{array}{c}\% \\
\text { Osteopenia }\end{array}$ & $\begin{array}{c}\% \\
\text { Osteoporosis }\end{array}$ & $\begin{array}{c}\mathrm{n}(\%) \\
\text { Deaths }\end{array}$ \\
\hline Women & 3945 & $0.403(0.069)$ & 38.3 & 33.7 & 28.0 & $1538(39.0)$ \\
\hline $50-54$ & 1050 & $0.453(0.050)$ & 70.2 & 25.3 & 4.5 & $135(12.9)$ \\
\hline $55-59$ & 840 & $0.421(0.055)$ & 46.1 & 39.5 & 14.4 & 175 (20.8) \\
\hline $60-64$ & 695 & $0.393(0.060)$ & 27.5 & 41.9 & 30.7 & 247 (35.5) \\
\hline $65-69$ & 752 & $0.365(0.064)$ & 16.4 & 34.7 & 48.9 & $475(63.2)$ \\
\hline $70-74$ & 577 & $0.352(0.063)$ & 12.0 & 29.8 & 58.2 & $477(82.7)$ \\
\hline $75-79$ & 31 & $0.341(0.081)$ & 16.1 & 22.6 & 61.3 & $29(93.5)$ \\
\hline Men & 2845 & $0.533(0.067)$ & 55.4 & 30.6 & 14.0 & $1638(57.6)$ \\
\hline $50-54$ & 225 & $0.564(0.050)$ & 77.8 & 20.0 & 2.2 & $40(17.8)$ \\
\hline $55-59$ & 793 & $0.552(0.056)$ & 67.6 & 27.1 & 5.3 & $258(32.5)$ \\
\hline $60-64$ & 700 & $0.539(0.061)$ & 56.1 & 32.7 & 11.1 & $378(54.0)$ \\
\hline $65-69$ & 606 & $0.520(0.069)$ & 46.4 & 33.7 & 20.0 & $468(77.2)$ \\
\hline $70-74$ & 494 & $0.501(0.073)$ & 36.0 & 34.4 & 29.6 & 467 (94.5) \\
\hline $75-79$ & 27 & $0.492(0.099)$ & 44.4 & 25.9 & 29.6 & $27(100.0)$ \\
\hline
\end{tabular}

$\mathrm{N}=$ total number of participants, BMD =Bone Mineral Density, $\mathrm{n}=$ number of participants who died during the follow-up period

Table 2. Number or proportions (\%) of participants in the Troms $\phi$ 4-study in groups: "Normal BMD", "Osteopenia" and "Osteoporosis"at baseline in 1994/1995. Number of deaths, person years (py) and mortality rate per 1000 py during 22 years follow up. Each variable listed in women and men.

\begin{tabular}{|c|c|c|c|c|c|}
\hline & $\mathbf{N}$ & Normal BMD & Osteopenia & Osteoporosis & Trend* \\
\hline \multicolumn{6}{|l|}{ Women } \\
\hline Number of participants & 3945 & 1512 & 1329 & 1104 & \\
\hline Number of deaths & 1501 & 327 & 498 & 676 & $<0.001$ \\
\hline Person years (py) & 3945 & 30032 & 24572 & 18112 & \\
\hline Mortality rate per 1000 py & 3945 & 10.9 & 20.3 & 37.3 & \\
\hline Age (years) & 3945 & $56.5(6.1)$ & $61.1(6.8)$ & $66.1(5.8)$ & $<0.001$ \\
\hline $\mathrm{BMD}\left(\mathrm{g} / \mathrm{cm}^{2}\right)$ & 3945 & $0.472(0.032)$ & $0.398(0.019)$ & $0.316(0.037)$ & $<0.001$ \\
\hline BMI $\left(\mathrm{kg} / \mathrm{m}^{2}\right)$ & 3937 & $26.6(4.5)$ & $26.2(4.5)$ & $25.2(4.4)$ & $<0.001$ \\
\hline Grip strength (bar) & 3931 & $0.79(0.20)$ & $0.73(0.18)$ & $0.66(0.18)$ & $<0.001$ \\
\hline Smoking & 3941 & & & & 0.138 \\
\hline Never smoker, $\%$ & & 43.2 & 45.4 & 40.9 & - \\
\hline Current smoker, $\%$ & & 30.2 & 27.9 & 32.5 & - \\
\hline Previous smoker, $\%$ & & 26.6 & 26.7 & 26.7 & - \\
\hline L-phys.act.<1 hour/week, $\%$ & 3938 & 25.4 & 26.3 & 29.6 & 0.044 \\
\hline H-phys.act.<1 hour/week, \% & 3903 & 81.9 & 86.0 & 90.4 & $<0.001$ \\
\hline Low education, $\%$ & 3915 & 55.2 & 60.8 & 70.2 & $<0.001$ \\
\hline Self-reported health status & 3939 & & & & $<0.001$ \\
\hline Poor $\%$ & & 2.5 & 3.1 & 4.9 & - \\
\hline Not so good $\%$ & & 42.6 & 46.5 & 52.5 & - \\
\hline
\end{tabular}




\begin{tabular}{|c|c|c|c|c|c|}
\hline Good $\%$ & & 47.9 & 44.6 & 38.9 & . \\
\hline Very good $\%$ & & 7.0 & 5.9 & 3.6 & - \\
\hline Stroke \% & 3929 & 1.2 & 2.1 & 2.5 & 0.042 \\
\hline Angina $\%$ & 3936 & 4.6 & 6.4 & 10.1 & $<0.001$ \\
\hline Myocardial infarction \% & 3932 & 1.9 & 3.2 & 4.0 & 0.004 \\
\hline Diabetes $\%$ & 3929 & 2.3 & 3.5 & 3.2 & 0.132 \\
\hline Asthma \% & 3927 & 8.0 & 8.9 & 9.0 & 0.577 \\
\hline \multicolumn{6}{|l|}{ Men } \\
\hline Number of participants & 2845 & 1575 & 870 & 400 & \\
\hline Number of deaths & 1596 & 740 & 530 & 326 & $<0.001$ \\
\hline Person years (py) & 2845 & 26944 & 13760 & 5068 & \\
\hline Mortality rate per 1000 py & 2845 & 27.5 & 38.5 & 64.3 & \\
\hline Age (years) & 2845 & $61.2(6.2)$ & $63.4(6.1)$ & $66.8(5.6)$ & $<0.001$ \\
\hline $\operatorname{BMD}\left(\mathrm{g} / \mathrm{cm}^{2}\right)$ & 2845 & $0.581(0.036)$ & $0.501(0.019)$ & $0.419(0.039)$ & $<0.001$ \\
\hline BMI $\left(\mathrm{kg} / \mathrm{m}^{2}\right)$ & 2843 & $26.6(3.2)$ & $25.6(3.3)$ & $24.9(3.8)$ & $<0.001$ \\
\hline Grip strength (bar) & 2831 & $0.89(0.21)$ & $0.83(0.20)$ & $0.72(0.19)$ & $<0.001$ \\
\hline Smoking & & & & & $<0.001$ \\
\hline Never smoker, $\%$ & 2844 & 20.9 & 17.5 & 12.8 & - \\
\hline Current smoker, $\%$ & 2844 & 27.4 & 33.0 & 40.8 & - \\
\hline Previous smoker, $\%$ & 2844 & 51.7 & 49.5 & 46.5 & - \\
\hline L-phys.act.<1 hour/week, $\%$ & 2828 & 25.1 & 25.0 & 27.5 & 0.603 \\
\hline H-phys.act. $<1$ hour/week, $\%$ & 2814 & 70.9 & 74.3 & 78.4 & 0.006 \\
\hline Low education, $\%$ & 2833 & 47.2 & 45.9 & 52.3 & 0.131 \\
\hline Self-reported health status & 2841 & & & & 0.014 \\
\hline Poor $\%$ & & 3.2 & 2.8 & 6.0 & - \\
\hline Not so good $\%$ & & 39.8 & 38.4 & 42.7 & - \\
\hline Good \% & & 50.9 & 53.4 & 47.7 & - \\
\hline Very good $\%$ & & 6.1 & 5.4 & 3.5 & - \\
\hline Stroke \% & 2834 & 2.7 & 3.2 & 6.3 & 0.002 \\
\hline Angina $\%$ & 2836 & 12.2 & 12.2 & 14.3 & 0.515 \\
\hline Myocardial infarction \% & 2836 & 9.8 & 10.7 & 12.3 & 0.325 \\
\hline Diabetes $\%$ & 2834 & 3.8 & 3.6 & 3.0 & 0.779 \\
\hline Asthma \% & 2833 & 7.4 & 6.1 & 9.1 & 0.161 \\
\hline
\end{tabular}

Abbreviations: L/H-phys.act. = Light/Hard physical activity, BMD = Bone Mineral Density, py = person years " $<1$ hour/week" contains both alternatives "none" and "less than one". "Low education" $=7$ years or less.

*Trend gives p-values based on linear regression for the continuous variables (Normal BMD coded 0, osteopenia coded 1 and osteoporosis coded 2) and chi square test for the categorical ones. 
Table 3. Hazard ratios (HR) with 95\% confidence intervals (CI) of mortality for BMD categories: "Normal, "Osteopenia" and "Osteoporosis" during 22 years follow-up from 1994/1995 to November 2016. Model 1-4 progressively adjusted for age, lifestyle- and health related covariates.

\begin{tabular}{|c|c|c|c|c|c|c|c|c|c|}
\hline \multirow{3}{*}{$\begin{array}{l}\text { Model adjusted for } \\
\text { Model 1: Age }\end{array}$} & \multirow{3}{*}{$\begin{array}{l}\text { BMD } \\
\text { Normal }\end{array}$} & \multirow{3}{*}{$\mathbf{N}$} & \multicolumn{3}{|c|}{ Women } & \multicolumn{4}{|c|}{ Men } \\
\hline & & & HR & \multicolumn{2}{|c|}{$95 \% \mathrm{CI}$} & \multirow[t]{2}{*}{$\mathbf{N}$} & \multirow{2}{*}{$\begin{array}{l}\text { HR } \\
1.00\end{array}$} & \multicolumn{2}{|c|}{$95 \% \mathrm{CI}$} \\
\hline & & & & & & & & & \\
\hline & Osteopenia & & 1.17 & 1.01 & 1.35 & & 1.14 & 1.02 & 1.28 \\
\hline & Osteoporosis & & 1.42 & 1.23 & 1.64 & & 1.62 & 1.41 & 1.85 \\
\hline & & 3818 & & & & 2747 & & & \\
\hline \multirow{4}{*}{$\begin{array}{l}\text { Model 2: Model } 1+\text { BMI, } \\
\text { education, physical activity, } \\
\text { smoking }\end{array}$} & Normal & & 1.00 & & & & 1.00 & & \\
\hline & Osteopenia & & 1.17 & 1.01 & 1.36 & & 1.13 & 1.01 & 1.27 \\
\hline & Osteoporosis & & 1.35 & 1.17 & 1.57 & & 1.45 & 1.26 & 1.67 \\
\hline & & 3818 & & & & 2747 & & & \\
\hline \multirow{4}{*}{$\begin{array}{l}\text { Model 3: Model } 2+\text { self- } \\
\text { reported health and chronic } \\
\text { diseases* }\end{array}$} & Normal & & 1.00 & & & & 1.00 & & \\
\hline & Osteopenia & & 1.18 & 1.02 & 1.36 & & 1.14 & 1.01 & 1.28 \\
\hline & Osteoporosis & & 1.34 & 1.16 & 1.55 & & 1.42 & 1.23 & 1.64 \\
\hline & & 3818 & & & & 2747 & & & \\
\hline \multirow{4}{*}{$\begin{array}{l}\text { Model 4: Model } 3+\text { grip } \\
\text { strength }\end{array}$} & Normal & & 1.00 & & & & 1.00 & & \\
\hline & Osteopenia & & 1.17 & 1.01 & 1.35 & & 1.13 & 1.00 & 1.27 \\
\hline & Osteoporosis & & 1.32 & 1.14 & 1.53 & & 1.37 & 1.19 & 1.58 \\
\hline & & 3818 & & & & 2747 & & & \\
\hline
\end{tabular}

*Chronic diseases include angina, asthma, stroke, myocardial infarction and diabetes. $\mathrm{N}=$ number of subjects included in analysis. 
Table 4. Hazard ratios (HR) with 95\% confidence intervals (CI) of mortality for BMD categories: "Normal, "Osteopenia" and "Osteoporosis" and after sustaining a hip fracture or osteoporotic fracture during 15 years follow-up from $1994 / 1995$ to March 2010. Model 1 minimally adjusted without fractures. Model 2 and 4 minimally adjusted and model 3 and 5 fully adjusted for age, lifestyle- and health related covariates in addition to hip fractures (model 2 and 3) and osteoporotic fractures(model 4 and 5).

\begin{tabular}{|c|c|c|c|c|c|c|c|c|c|}
\hline \multirow{5}{*}{$\begin{array}{l}\text { Model adjusted for } \\
\text { Model 1: Age }\end{array}$} & \multirow{4}{*}{$\begin{array}{l}\text { BMD } \\
\text { Normal } \\
\text { Osteopenia }\end{array}$} & \multicolumn{4}{|c|}{ Women } & \multicolumn{4}{|c|}{ Men } \\
\hline & & \multirow[t]{2}{*}{$\mathbf{N}$} & \multirow{2}{*}{$\begin{array}{l}\text { HR } \\
1.00\end{array}$} & \multicolumn{2}{|c|}{$95 \% \mathrm{CI}$} & \multirow[t]{2}{*}{$\mathbf{N}$} & \multirow{2}{*}{$\begin{array}{l}\text { HR } \\
1.00\end{array}$} & \multicolumn{2}{|c|}{$95 \% \mathrm{CI}$} \\
\hline & & & & & & & & & \\
\hline & & & 1.25 & 1.02 & 1.54 & & 1.06 & 0.92 & 1.23 \\
\hline & Osteoporosis & & 1.46 & 1.19 & 1.79 & & 1.54 & 1.30 & 1.82 \\
\hline & & 3809 & & & & 2745 & & & \\
\hline \multirow{4}{*}{$\begin{array}{l}\text { Model 2: Model } 1 \text { + hip } \\
\text { fracture }\end{array}$} & Normal & & 1.00 & & & & 1.00 & & \\
\hline & Osteopenia & & 1.24 & 1.01 & 1.53 & & 1.05 & 0.90 & 1.21 \\
\hline & Osteoporosis & & 1.40 & 1.14 & 1.72 & & 1.52 & 1.28 & 1.79 \\
\hline & & 3809 & & & & 2745 & & & \\
\hline \multirow{3}{*}{$\begin{array}{l}\text { Model 3: Model } 2+\text { BMI, } \\
\text { education, physical activity, } \\
\text { smoking, self-reported } \\
\text { health, grip strength and } \\
\text { chronic diseases* }\end{array}$} & Normal & & 1.00 & & & & 1.00 & & \\
\hline & Osteopenia & & 1.24 & 1.01 & 1.52 & & 1.00 & 0.86 & 1.16 \\
\hline & Osteoporosis & 3809 & 1.30 & 1.05 & 1.61 & 2745 & 1.25 & 1.05 & 1.49 \\
\hline \multirow{4}{*}{$\begin{array}{l}\text { Model 4: Age, osteoporotic } \\
\text { fracture }\end{array}$} & Normal & & 1.00 & & & & 1.00 & & \\
\hline & Osteopenia & & 1.24 & 1.01 & 1.52 & & 1.04 & 0.90 & 1.21 \\
\hline & Osteoporosis & & 1.42 & 1.15 & 1.74 & & 1.50 & 1.27 & 1.77 \\
\hline & & 3809 & & & & 2745 & & & \\
\hline \multirow{3}{*}{$\begin{array}{l}\text { Model 5: Model } 4+\text { BMI, } \\
\text { education, physical activity, } \\
\text { smoking, self-reported } \\
\text { health, grip strength and } \\
\text { chronic diseases* }\end{array}$} & Normal & & 1.00 & & & & 1.00 & & \\
\hline & Osteopenia & & 1.23 & 1.00 & 1.51 & & 1.00 & 0.86 & 1.17 \\
\hline & Osteoporosis & 3809 & 1.30 & 1.05 & 1.61 & 2745 & 1.23 & 1.04 & 1.47 \\
\hline
\end{tabular}

*Chronic diseases include angina, asthma, stroke, myocardial infarction and diabetes. $\mathrm{N}=$ number of subjects included in analysis. 


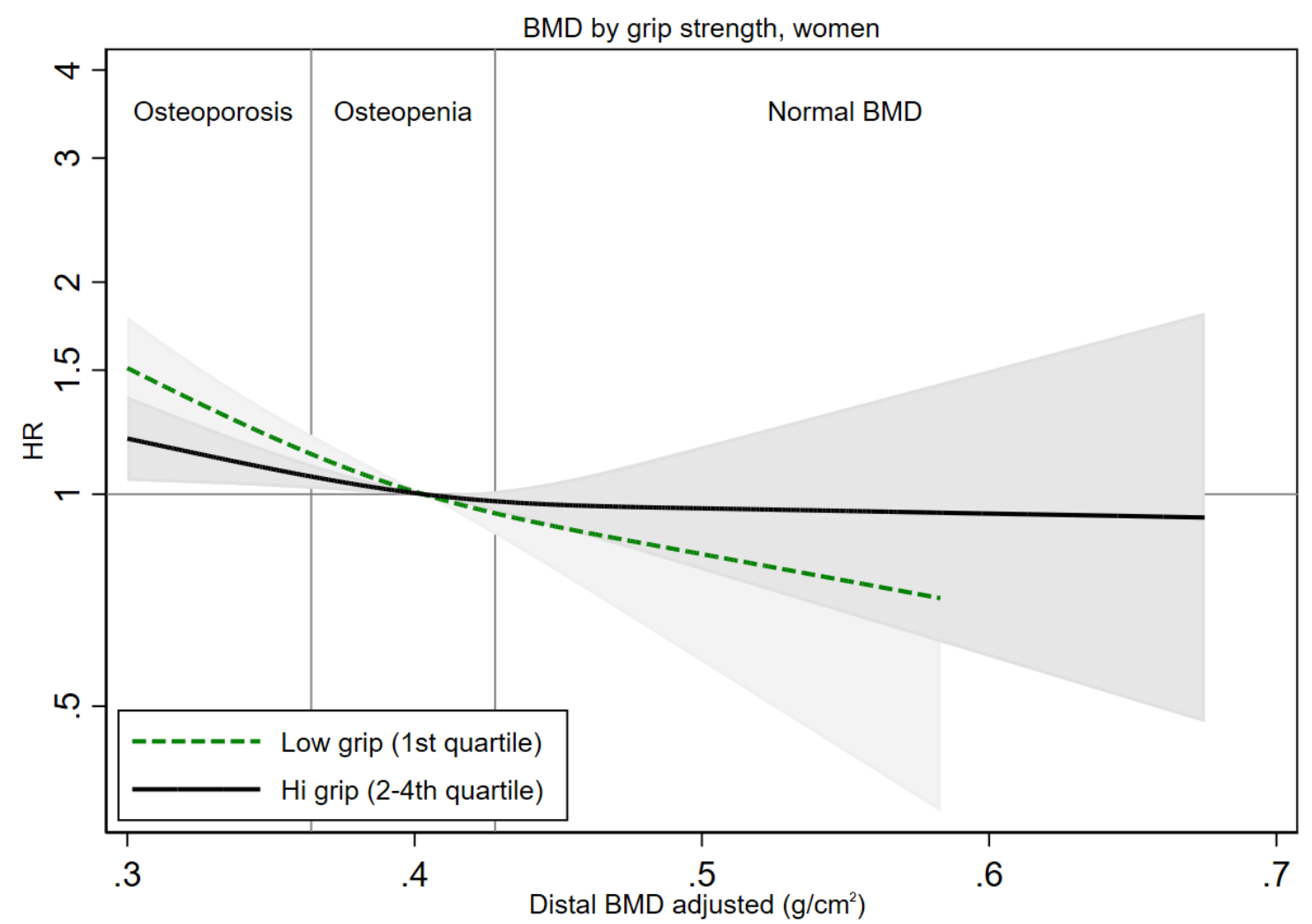

Figure 1: Mortality hazard ratios with 95\% confidence intervals across the range of distal forearm BMD in women with low grip strength (dashed curve) and in women with normal or high grip strength (solid curve). Mediating effect not significant.

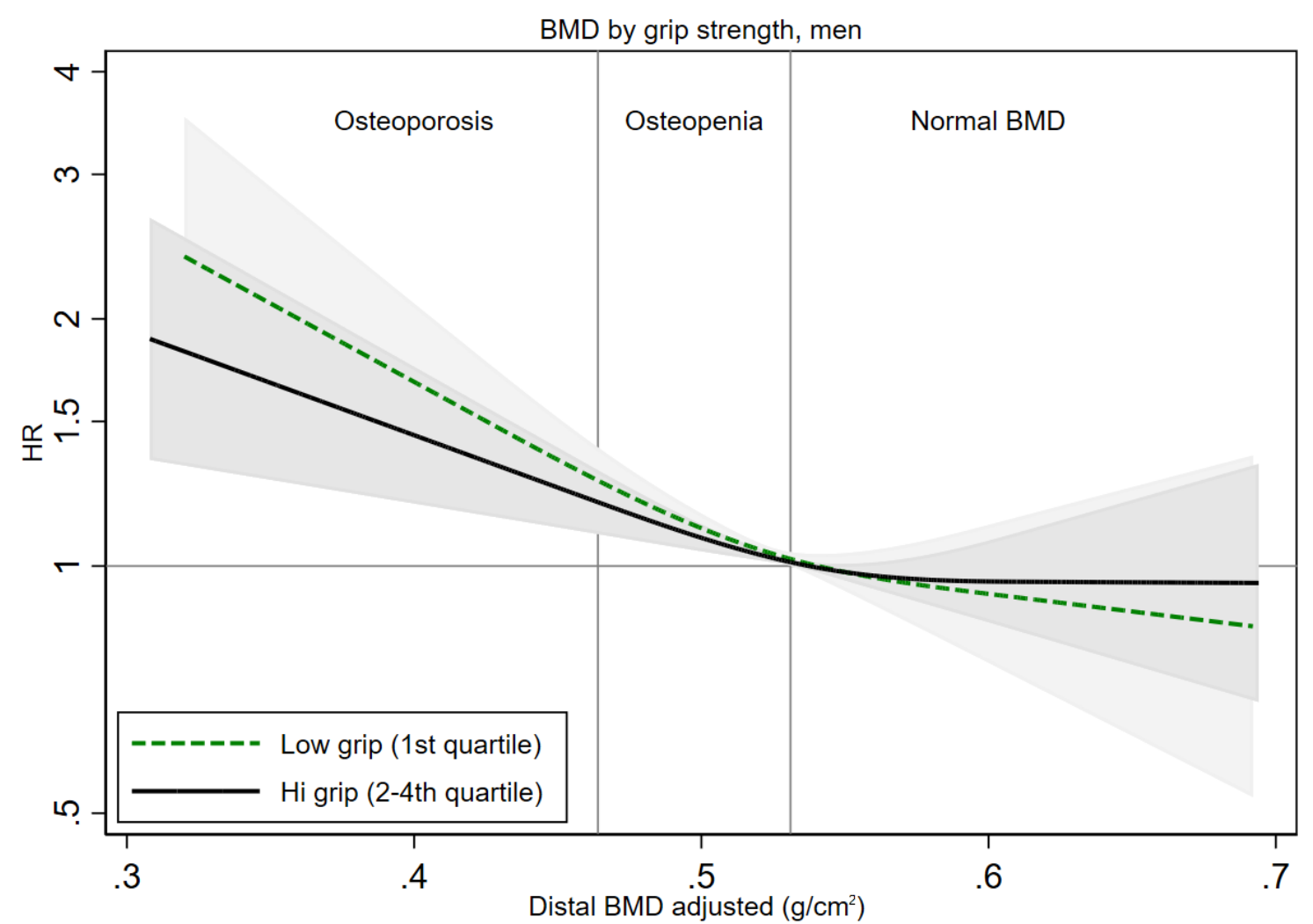

Figure 2: Mortality hazard ratios with $95 \%$ confidence intervals across the range of distal forearm BMD in men with low grip strength (dashed curve) and in women with normal or high grip strength (solid curve). Mediating effect not significant. 